LA-UR- $03-0534$

Approved for public release; distribution is unlimited.
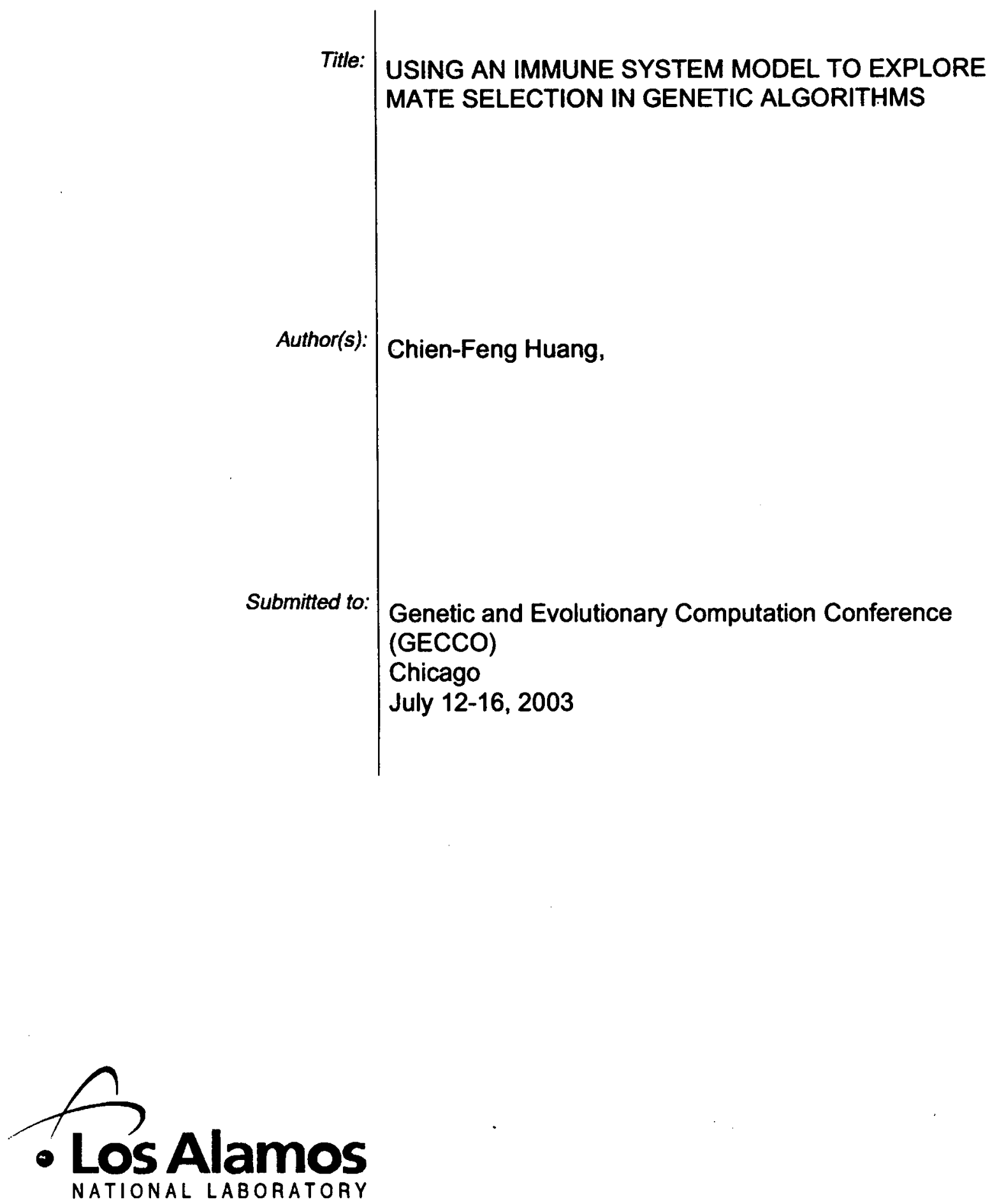

Los Alamos National Laboratory, an affirmattve action/equal opportunity employer, is operated by the University of Calfornia for the U.S. Department of Energy under contract W-7405-ENG-36. By acceptance of this article, the publisher recognizes that the U.S. Government retains a nonexcluslve, royalty-free license to publlsh or reproduce the published form of this contribution, or to allow others to do so, for U.S. Government purposes. Los Alamos National Laboratory requests that the pubilsher identlfy this article as work performed under the auspices of the U.S. Department of Energy. Los Alamos Natlonal Laboratory strongly supports academic freedom and a researcher's ifght to publtsh; as an institution, however, the Laboratory does not endorse the vlewpoint of a publication or guarantee its technical correctness. 


\title{
Using an Immune System Model to Explore Mate Selection in Genetic Algorithms
}

\author{
Chicn-Feng Huang \\ Morlcling, Algorithms, and Informatics Group (C.CS-3); \\ Computer and Computational Scicuces. \\ Los Alamos Narional Laboratory, MS B250, \\ Los Alamos, Nit 87545, LSA \\ cfhuang@lanl.gov
}

\begin{abstract}
In the setting of multimodal function optimization, cnginecring and machine learning, identifying multiple peaks and maintaining subpopulations of the scarch space are two central themes when Genetic Algorithms (GAs) are cmployed. In this paper, an immunc system model is aclopted to develop a framework for exploring the role of mate sclection in G.As with respect to these two issues. The cxperimental results reported in the paper will slued more light into how mate selection schemes compare to traditional selection schemes. In particular, we slow that dissimilar mating is bencficial in identifying multiple peaks, yet Larmful in maintaining subpopulations of the scarch space.
\end{abstract}

\section{Introduction}

In the setting of multimodal function optimization, cenginecring and machine learning, there are two important issues when the GA is cmployed: (1) how fast can the GA discover one or several peaks? And (2) can the GA maintain diverse subpopulations in different parts of the search space?" In this paper, we intend to use the mate-selection framework proposed in [7] and present the research work for investigating tlinse two themes. In [7], it was shown that mate solection plays a crucial role in GA's search performance. In a nutshell, the dissimilarity-based matc selection schemes facilitate locating a single, best-so-far solution at the expense of gencrating lethal offspring: and the similarity-bascd mate selection schemes enlance selection pressure toward highly-fit individuals such that the GA's population converges rapidly to a certain region of a fitness landscape. As such, for the first question, we would expect the dissimilarity-based mate selection to improwe the GA's scarch performance with respect to that metric. On the other hand, our empirical results so far have slowed that simple GAs with the mate selection schemes are all sulbject to convergenee (i.e., the simple GAs

\footnotetext{
${ }^{1}$ The first issuc was bricfly discussed in [7]. For the second issuc, there are some practical problems where maintaining subpopulations are critical. An example is the application of geuctic approach to deccntralized PI controller tuning for multivariable. processes in [12].
} 
cannot maintain sulppopmlations). Thus for the second question, wo intend to cmploy Smith et al.'s immune system model [11], which was shown to be able to maintain diverse subpopulations, in order to offer additional insights into how the mate sclection schemes compare to traditional selection schemes. In particular; wo are interested in studying how different mate choices affect the capability of Smith et al's approach for maintaining subpopulations. Since it has ben shown, in [7], that the dissimilar mating mochanisms are harmful in the sonse of producing more uscless hybrids, we expect that such mating proferences will reduce the proportions of individuals in subpopulations. If so, the next question would be to study if reducing the probability of dissimilar mating (or increasing the probability of similar mating) can improve the capability for maintaining subpopulations.

This paper presents the preliminary results wo obtained while investigating the role of mate sclection in the two issues discussed above. Before delving fully into this paper, howerer, it is important to briefly reviow Goldberg and Richardson's fitness sharing mochanism [3] that serves as an idcalized approach for maintaining population diversity, and prescent Smith et al.'s immune system modol to discuss how it implements a form of implicit fitness sharing so as to facilitate formation of sulpopulations. We then summarize the relevant framowork for studying mate selection proposed in [7]. Section 3 presents $\mathrm{cx}$ perimental results that answer the two questions mentioned above. Finally, this paper is concluded with the insights obtained for the mate selection schemes and future rescarch lines.

\section{Relevant Work in Prior GA Research}

\subsection{Fitness Sharing}

Fitness sharing was an idca motivatcel by Holland's discussion [6] in which the number of individuals occupying a niche is limited to that niche's carrying capacity. Goldberg and Richardson [3] then introduced a fitness sharing mochanism that, induces population diversity by penalizing individuals for the presence of similar individuals in the population. The technique they proposed was shown to be an effective methorl for maintaining subpopulations orer scveral high-fitness regions of the scarcli space. Howerer, it has two scrions limitations: (1) the peaks must be cquidistant, or nearly so, and (2) setting $\sigma_{s}$ (a critical parameter in the fitness sharing scheme that represents a cutoff distance, beyond which no sharing will occur) requires knowledge about the number of peaks in the search space. These limitations arise from the fact that fitness sharing is defined explicitly.

To avoid the difficulty of appropriately choosing $\sigma_{s}$ Smith, Forrest and Perclson [11] introduced an algorithm that does not require explicit construction of the sharing function. Their approach can implicitly achicve fitness sharing that discovers for itsolf how many pealis are in the scarch space (including the case of not mually spaced peaks), and allocate trials appropriatcly. The idea is to use the motaphor of biological immune systems which can maintain the diversity 
necded for it to detect multiple antigens. Then the GA, combined with the immunc systcm idea, offectively distributes the population over scveral high-fitness arcas of the scarch space.

\subsection{Binary Immune System Model}

The immuno system model considered in this paper is based on a model introduced by Farmer et al. [1], where both antigens and antibodies are represented by binary strings. It is a simplification from the real biology in which genes are specified by a four-letter mucleic acid alphabet and recognition betwen antibodics and antigens is based on their threc-dimensional shapes and physical propertics. However, this abstract model of binary strings is rich onough for $\mathrm{x}-$ ploring how a relatively small number of recognizers (the antibodies) can crolve to recognize a much larger number of different patterus (the autigens).

In this binary immunc systcm modd, recognition is evaluated through a string matching procedure. The antigens are considered fixed, and a population of $N$ antibodics is colved to recognize the antigens using a GA. For any set of antigens, the goal is to obtain an antibody cover-a set of autibodies such that cach antigen is recognized by at least one antibody in the population. Maintaining diverse antibodics is crucial for obtaining a cover [11].

An antibody is said to match an antigen if their bit strings are complementary (maximally differcut). Since cach antibody may have to match against sevcral different autigens simultancously, we do not require perfect bit-wise matching. Many possible match rulos are plausible plyssiologically (Sce [10] for $\mathrm{cx}-$ amples). The degrec of match is quautified by a class of match score functions $M:$ Antigen $\times$ Antibody $\rightarrow$ 次. For instance, $M I$ can simply count the number of complementary bits or $M$ can identify contiguous regions of complementary bitwise matches within the string.

Smith et al. [11] adopted a model in which a fixed set of antigens is given, and the antibodics are initialized either to be completely random (to sec if the GA can learn the correct antibodies) or initially given the answer by setting the population to include the correct antibodies (to test the stability of the answer). Their mochanism for fitness scoring is as follows:

1. A single antigen is randomly selected from the antigen population.

2. From the population of $N$ antibodies a randomly selected sample of size $\sigma$ is taken without replarement.

3. For cach antibody in the sample, match it against the sclected antigen, determine the mumber of bits that match, and assign it a match scorc.

4. The antibody in the sample population with the lighest match score is detcrmincd. Tics are broken at random.

5. The match score of the winning antibody is added to its fitness. The fitness of all other antibodies remains unchanged.

6. This process is repeated for $C$ cycles (typically one to three times the number of antiborlics). 
In this scheme, since an antibody's fitness is increased only if it is the best. matching antiloody in the sample, the fitness values of antibodies are interdependent. In [11] Smith et al. showed analytically how this procedure implicitly cmbodies fituness sharing. Furthermore, Forrest ct al. [2] reported that this scheme can maintain subpopulations of antibodies that cover a set of antigens.

\subsection{Mate Selection Schemes}

Based on the idea of "assortative mating" used in biology, [ $\overline{7}]$ proposed a frame work to investigate the role of mate sclection in GA's search power. ${ }^{2}$ Simply stated, the goal was to shed more light into how specific mate sclection sclicmes compare to traditional sclection schemes. In case of similar mating, similar individuals are chosen for mating; in case of dissimilar mating, dissimilar individuals will mate with cach other. That is, the selection-for-mating step of a simple GA [9] is modified as:

During carh mating crent, a binary tournament sclection ${ }^{3}$ - with probability one the fitter of the two randomly sampled individuals is chosen-is run to pick out the first individual, then choosing the mate according to the following schemes:

Tournament Selection (TS): Run the binary tournamont scloction again to choose the matc.

Tournament Dissimilar Mating (TDM): Run the binary toumament sclection two more times to choose two candidate partners; then the one more dissimilar to the first individual is selected for mating.

Tournament Similar Mating (TSM): Run the hinary tournament, seloction two more times to choose two candidate partucrs: then the one more similar to the first inclividual is solected for mating.

Random Dissimilar Mating (RDM): Randomly choose two candidate part-ners; then the one more dissimilar to the first individual is sclected for mating.

Random Similar Mating (RSM): Randomly choose two candidate partners: then the one more similar to the first individual is sclected for mating.

We use the Hamming distance as the similarity metrice Notice that in the mate sclection schemes above if the two candidates are of the same Hamming distance to the first individual, then one of them is randomly selected.

In the five approaches above, the first individual is always sampled by the regular tournament selection. For TDM and TSM, there are two ways to affect an individual's probalility of being selected. The first results from the fitness craluation explicitly defined by a given test function. The second is from the preference of each individual over other individuals that possess entain characteristics. The two sources complicate the probability of an individual being

\footnotetext{
2 Sec [7] for a comprehensive litcrature review of the relating mate-sclection work in prior G.A rescarch and a detailed discussion on why the framework was proposed.

3 Touruament sclection is employed here for low computational cost.
} 
sclected for actual mating. It is expected that tournament sclection contributes more sclection pressure toward highly-fit individuals, and the mate preference refines the scarching for mates. As for RDM and RSM, the sclection pressure is reduced by removing the tomuament solection acting upon the candidate mates. The only source that affects the mate selection probability is preciscly the mating proforence, which cxots a solcction pressure on the population based on genotype.

\section{Experimental Results}

To illustrate the effects of mate sclection on the subpopulation-maintaining ability of Smith ot al.'s immune system algorithm (we call it the diversity algorithm from hore on). wo use a simple cxample in which antigen populations cannot. be matched by a single antibody type. Consider an antigen population that is composed of $50 \% 000 \ldots 000$ (all 0 's) and $50 \% 111 \ldots 111$ (all 1 's). In order for an autibody population to recognize these antigens, there would need to be some antibodics that are all 1's and others that are all 0's. Thus, a solution to this problem requires the GA to maintain two different, solutions simultanmously. This is an example of a "multiple peaks" problem because there are two incompatible solutions that are maximally different. Typically, on multiple-poaks problems it is difficult for simple GAs to distribute the population over screral peaks of a fituess landscape (two different subpopulations of antibodies that match two types of antigens, in this case). This is because the sclection pressure in a simple standard GA usually entails strong convergenee tendency to only one peak. Even without sclection pressure, genctic drift due to sampling cror can still lead the GA to converge on one of the poaks [4].

Forrest et al. [2] reported in their numerical experiments that the GA with the diversity algorithm can effectively avoid strong convergence to one peak and distribute-the population over multiple peaks. As has been discussed in the beginning of this paper, we expect the mate selection schemes play an important role in maintaining subpopulations. In particular, our objective is to address the following questions concerning the capability of the GA, along with Smith's algorithm, for maintaining subpopulations:

- Can the GA with different matc sclection schemes maintain stable subpop)ulations of antibodies for recognizing different antigens, or does it always converge on one peak? If it can maintain diverse subpopulations, then

- Is the proportion of antibodics in cach subpopulation being affoctod by different mating preferences?:

- Do different mating preferences have influence on the discovery time of antigens:?

In light of pattern-recognition, Forrest et al. [2] pointed out that the immunc system necds to recognize bactcria patially on the basis of the cxistence of

\footnotetext{
${ }^{4}$ How many autibody representatives must be in the population for an autigen to be. iclentified is critical. Sce [2] for a detailed discussion.
} 
certain unusual molccules that are inhorently different from human colls, since many bacteria have cell walls mado from polymers that do not occur in humans. With this as motivation. we study the GA's ability to detect common patterns (building blocks) in the antigen population and adopt the building-block idea in [6] to calculate fitnesses of antiborlies.

Table 1. Building blocks of antigens

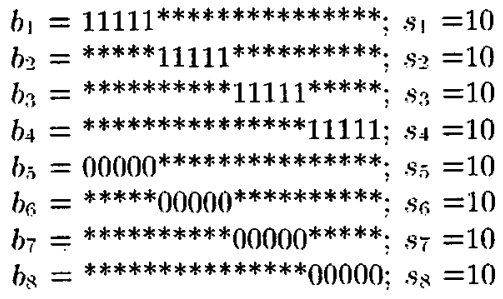

Table 1 illustrates the building blocks of antigens $111 \ldots 1$ and $000 \ldots 0$ (string lengtll is of 20 bits $\left.^{5}\right)$. An antibody is said to match an antigen if its bit string is complementary to the antigen at certain building blocks. Specifically, the match score function $M I_{b}$ is to identify the building blocks for which an antibody matches an antigen, and then assign corresponding scores to that antibody. For example, given an antigen $111 \ldots 1$, an antibody with the first five and the last. five bits being all 0 's will recoive score $s_{1}+s_{1}=20$, since these ten bits are complemontary to those of the antigen.

Smith et al. [11] considered two cases for the score calculation of antibodiesperfect match and partial match. In casc of perfect match, an antibody recoives a non-zero score only if it perfectly matches the antigen. In case of partial match, an antibody receives a non-zero score if it partially matches the antigen. In terms of the distance $d_{i j}$ betwen antibody $i$ and antigen $j$, partial match indicates the degree by which an antibody matches an antigen - i.c., the nmmber of bits of an antibody that are complementary to the corresponding bits of an antigen. The degree of match detcrmines the specificity of an autibody. For example, if $d_{i, j}=0$, the matching is completely specific (that is, the antibody must perfoctly match the antigen), but if $d_{i j} \neq 0$, it is partially matched. The conscquence of a partial matching rule is that there is a trade-off between the number of antibodics used and their specificity - as the specificity of antibodies increases, so does the number of antibodies required to achieve a certain level of detection [j].

For the scoring rulc discussed in the building-block-based recognition prob$\mathrm{lcm}$, we can also cxpand its definition by allowing partial match. In other words.

\footnotetext{
5 The small string length here scrves woll for illustrating the effect of the mate sciection schemes. We current have some results for larger string lengths that arc cousistent. with the results obtained for the small string length.
} 
Table 2. Illustration of the immunc-bascd GAs.

1. Randomly gencrate an initial population of $n$ autibodics.

2. Evaluate antibodies' fitnesses by the six steps of the diversity algorithm.

3. Repcat until $n$ offspring have becn created.

a. sclect a pair of parents for mating by particular sclection sclemes;

b. apply crossover operator;

c. apply mutation opcrator.

4. Reset all the uew individuals' fituesses to zero and replace the current populatiou with the new population.

5. Go to Stcp 2 until torminating condition.

if an antibody matches an antigen at all the bits of a building block, it is a perfect. building-block match: if not all the bits of that building block are required for matching, it constitutes a partial building-block match. Therefore, the profect. building-block match case is that an antibody seores if all of its bits at a building block are complementary to those of an antigen. On the other hand, a case for partial match could allow an antibody to score with only $80 \%$ bits (i.c., 4 bit.s in case of the building blocks shown in Tallo 1) of a building block at which it. matches an antigen. The result of this flexible scoring is a smaller population size required to achicre a certain level of recognition performance. In this paper, we mostly concentrate on this latter case for calculating antibody scorcs. (In casc of $100 \%$ building-block match, a fcw cxporimcuts conducted so far have shown similar qualitative results as the $80 \%$ building-block match case, but it requires much larger population sizes, i.e., much higher computational costs, to achicre similar levels of performance.)

\subsection{Effects of Mate Selection on Maintaining Subpopulations}

To address the questions mentioned in the beginning of this section we conduct a series of GA cxperiments using the diversity algorithm. The illustration of the immuno-based GAs is shown in Table 2. ${ }^{6}$ Our first objective is to inrestigate effects of mate selection on the diversity algorithm's sulpopmlation-maintaining

\footnotetext{
${ }^{6}$ Since in the cliversity algoritlum the match scores of winning antiborlics are continnously accumulated, after cach gencration their fitucss values can be large. Thus at step 4 of Table 2 we reset the fitnesses of the new population's individuals to zcro after cach gencration to prevent fitucsses from unlimited increase.
} 
ability. Cnless stated otherwise, these experiments use an antibody population size of 100 , crossover rate of 0.7 , mutation rate of 0.005 , and ran for $150 \mathrm{gen}-$ crations. The antigen population is $50 \% 000 \ldots 0$ and $50 \% 111 \ldots 1$, and both antigens and antibodies are binary strings of length 20 . The number of samples: $\sigma$, is 10 , which is $10 \%$ of the population size. We choose this value because Smith ct al.'s analysis suggests that too small or too large a sample size cannot show fitness sharing's effect. In addition, as mentioned in the preceding section, the number of cycles $(C)$ does not have a bearing on the antibodies' expected fitnosses, 100 cycles (i.c., population size) used for each gencration turned out to scrve well for displaying subpopulation-maintaining results. Thus the total funetion cvaluations for each rum are gencrations $\times$ cyclos $\times$ sauple size, which equal 150,000 .

Fig. 1 illustrates the experimental results of the diversity algorithm (averaged over 50 runs), cvolved by the GAs with TS, TDM, TSM, RDM and RSM.
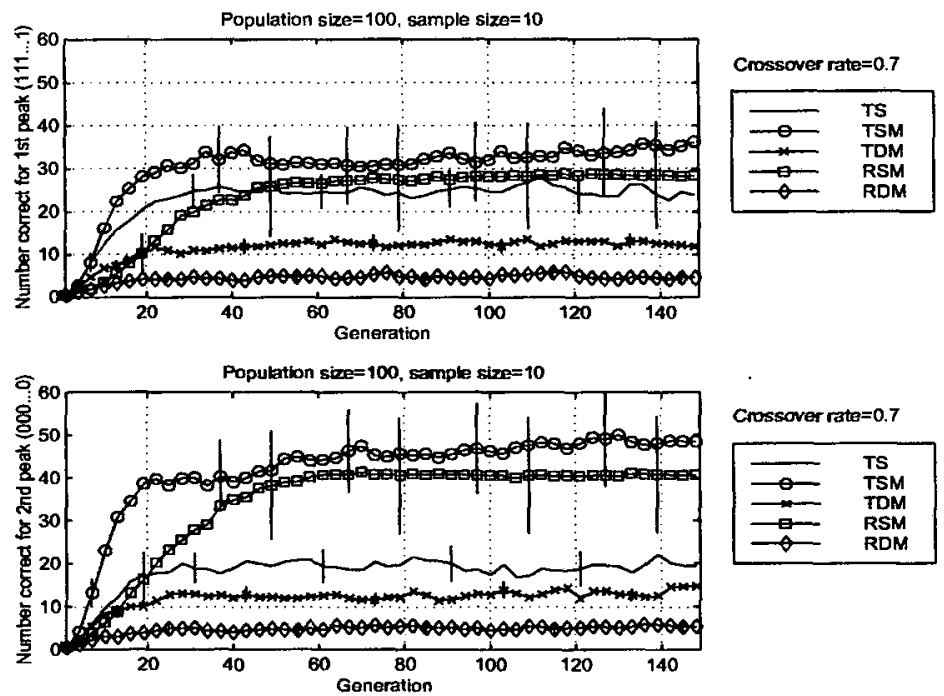

Crossover rate $=0.7$

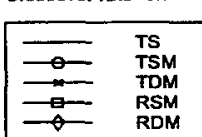

Fig. 1. The number of antibodics that correctly recognize autigens

These are the results for the numbers of antibodies that recognize antigens when all four building blocks are $80 \%$ correctly matched. Note that only the curves with small crror bars ( $95 \%$ confidence intervals ${ }^{7}$ ) can be used for reliable. judgements (we will discuss the reason for the larger crror bars sliortly), and thus the results for TS, TDM and RDMI can be compared. It is clear that the

\footnotetext{
${ }^{7}$ The vertical bars overlaying the metric curves throughout this paper represent the
} 95-percent confidence intervals calculated from Student's t-statistic: [8]. 
dissimilar mating schemes, TDM and RDM, gencrate less desired antibodics than the regular tommament selection. The reason is in the following:

When crossover is turned on (crossover rate is $\bar{T}$, in this case), the dissimilaritybascd mate sclection increases the probability of producing usciess hybrids-c.g., given an individual $111 \ldots 1$, and two candidate mates $111 \ldots 1$ and $000 \ldots 0$, the GAs with the dissimilar mating schemes tend to choose 000 . . . o for mating with $111 \ldots 1$, and the crossing-over between these two strings generates offspring that fall into the valley between the two peaks. Therefore, TDM and RDM maintain a smaller fraction of desired antibodies.

On the other hand, we see that TDM gencrates a larger fraction of desired antibodics than RDM. The difference between theses two schemes is the method of solecting the second individual for mating-that is, in TDM fitter individuals have higher probalilities of being selected as mates, but this is not the case for RDM. As a result, TDM can pick ont more individuals from the two peaks than RDM, which in turn increases the proportion of desired antibodies.

A remedy for the problem of producing uscless hybrids would be to reduce dissimilar mating rates. In terms of the cxample above, the regular tournament selection confers $111 \ldots 1$ and $000 \ldots 0$ with oqual probability of being sclected for mating, thereby reducing the likclihood of two mating individuals chosen from the two peaks. However, if individuals tend to sclect similar mates, the solection pressure toward these individuals may be strong cnough that the GA's population converges on only one peak. If this is the case, the diversity algorithm's capability for maintaining subpopulation is degraded.

The larger cror bars for TSM and RSM in Fig. 1 illustrate this situation. Since TSM and RSM induce too strong a selection pressure, most of the GA's population members converge to only one peak. At generation 150 , the GA with TSM has 20 (out of 50 ) runs in which most of the individuals converge to all 1 's, and in 14 (out of 50 ) runs most of the individuals converge to all 0's, and there are 16 runs in which the two peaks are present, simultaneonsly. In case of RSM, there are 17 rums in which most of the individuals converge to all 1 s, 21 runs in which most of the individuals converge to all 0 's, and 12 runs where the two peaks are lost.

As a further illustration, Fig. 2 is the experimental results of a typical rum for the mumber of desired autibodics obtained based on TSM. This figure shows that $000 \ldots 0$ are drown out by $111 \ldots 1$ after generation 60 , although they do show up in caulier gencrations. This is because in TSM, similar individuals are always choscn as matcs (with probability onc) - a selection pressure toward similar mates enhances the convergenes on one peak.

\subsection{Effects of Mate Selection on the Discovery of Peaks}

In the immune system problem considered, thus far we have ben conerned with maintaining desired antiloody subpopulations. However, there is another relcvant. issue wo have not yet studied: the formation of the antibody sulbpopulations requires these antibodies to be discovered first. This is equivalent to the problem 


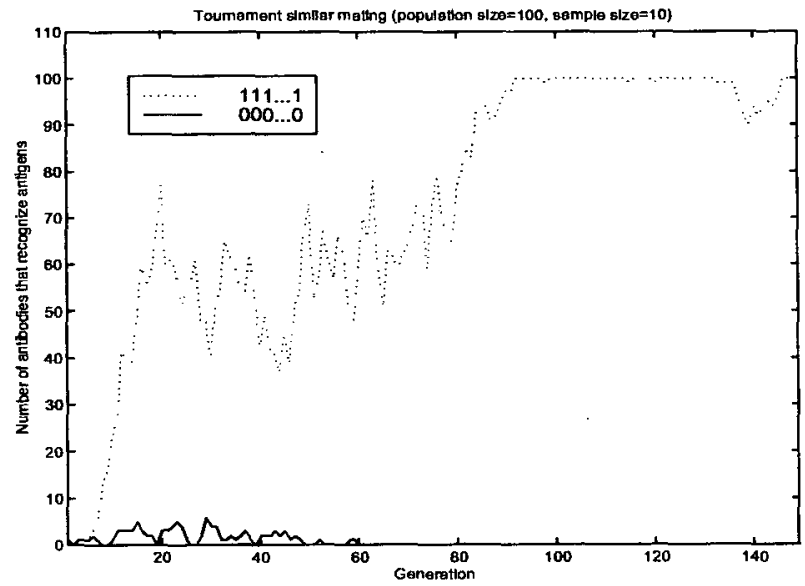

Fig. 2. The number of antibodics that correctly recognize autigcus (based on the tournament similar mating), where all portion of the solid line (i.c., corresponding to $000 \ldots 0)$ after geucration 10 is on the 0 level

of finding multiple peaks. Since it has becn shown, in [ $\overline{7}]$, that the dissimilaritybased mate selection facilitates locating a single, best-so-far solution, we are interested in investigating if dissimilar mating is also more bencficial in finding multiple peaks than traditional soloction schomes.

Table 3. The mean function evaluations of discovering antibodics $111 \ldots 1$ and $000 \ldots 0$ (over 50 runs)

\begin{tabular}{|c|c|c|c|c|c|}
\hline Antibody & TS & TDII & RDM & TSM & R.SW \\
\hline $111 \ldots 1$ & $2340(368)$ & $2460(333)$ & $2460(272)$ & $2440(204)$ & $3060(338)$ \\
\hline $000 \ldots 0$ & $2300(206)$ & $2540(323)$ & $2320(270)$ & $2180(224)$ & \\
\hline
\end{tabular}

Table 3 displays the averaged mean function evaluations (over 00 runs) of discovering $111 \ldots 1$ and $000 \ldots 0$. These results show no obvious difference betwoen various mate selection schemes for finding the two peaks, except that there aue two runs where $000 \ldots 0$ was not found by the RSM GA. and this GA uscd a bit more craluations to locate $111 \ldots 1$ than the other GAs. A closer inspection again shows the selection pressure toward similar individuals led the two particular runs of the GA to converge on $111 \ldots 1$, thereby precluding the discovery of the other peak. However, as population size decreases, the discrepancies betwen these mating schemes become more obvious. Table 4 illustrates the results for the number of runs (out of 50 ) in which antibodies $111 \ldots 1$ and 000 ...0 are discovered, respectively, based on population size 20 and sample size 
2 (other parameter values remain unchanged). It is clear that the dissimilaritybased mating preferences facilitate locating two peaks. This is again because the similar mating schemes introduce a selection pressure strong enongh that the corresponding GAs show inferior performance. All this confirms with our expectation that the dissimilarity-based mate sclection is bencficial in locating multiple poaks.

Table 4. The number of runs (out of 50 ) in which autibodics $111 \ldots 1$ and $000 \ldots 0$ are discovered

\begin{tabular}{|c|c|c|c|c|c|}
\hline Autibody & TS & TDM & RDAI & TSM & RSM \\
\hline $111 \ldots 1$ & 20 & 34 & 40 & 18 & 23 \\
\hline $000 \ldots 0$ & 28 & 37 & 34 & 23 & 23 \\
\hline
\end{tabular}

\section{Conclusions and Future Work}

In this paper, we have described Smith ot al.'s immune system model in which subpopulations can be maintained through specific intcractions among the strings. Wo have emphasized the performance of the GA in the binary immune system model. investigating how mate selection affects the GA's subpopulationmaintaining albility and the effects of mate selection on the discovery of multiple peaks. Botll of these issues are important in the setting of multimodal function optimization, enginecring and machine learning.

In studying the subpopulation-maintaining problem, the results illustrate that the dissimilar mating sclomes are harmful in the scuse of producing more letlat offspring. Consequently, the proportion of individuals that are representatives of different antilodies is reduced. We then showed that reducing the probalility of dissimilar matings can remedy this problem. Wo also hoped to improve the GAs' performance by further increasing similar mating rates. However, as shown by the results obtained for TSM and RSM, they introduce a selection pressure strong enough that the population converges on only one peak.

In studying the peaks-identifying problem, wo showed that the dissimilaritybased mate selection schemes facilitate locating multiple peaks of the fitness landscape. This is a crucial extension of the results obtained in [7], where dissimilar mating is shown to be more advantagcous in finding a single, best-so-far solution.

Since the pattern-recognition strategy in our approach was based on schema detcetion, it is worth further exploration because in real problems when there are many more antigens than antibodies, antibodins noed to detect common regions. In future work, we also hope to cxtend the results of schema detection and multiple-peaks identification to more realistic scale of antigens and antibodics. 
Finally; we would like to develop an analytical analysis to cnlaune our understanding for mate selection in the context of the immune-GA-basod system.

\section{Acknowledgments}

The anthor wonld like to thank John Holland, Rick Riclo for thcir advice, and Bol Lindsay, Ted Bolding, Lecaun Fu, Tom Bersano-Begey and Bill Rand for their comments and suggestions.

\section{References}

1. Farmer, J. D., Packard, N. H., and Pcrelson, A. S.: The Immune System, Adaptattion, and Machine Lcarning. In D. Farmer, A. Lapcdes, N. Packard, aud B. Wendroff (Eds.): Evolution, Games and Lcarning. NortlhHollaud (1986). (Rcpriutcd from Physica, 22D, 187-204)

2. Forrest, S., Javornil, B., Smith, R. E., and Perelson, A. S.: Lsing Genetic Algorithms to Explore Pattom Recoguition in the Immune Systcm. Evolutionary Computation; 1(3) (1993) 191-211.

3. Golklberg, D. E. and Richardson, J.: Genctic Algorithons with Sharing for Multimodal Function Optimization. Genctic Algorithms and Their Applications: Procecdings of the Second Interuational Couference on Genetic: Algorithms (1987) 4149.

4. Goldberg, D. E. and Scgrcst, D.: Finite Markov Chain Awalysis of Genctic Algorithms. Interuational Conference on Genetic Algorithms, 2 (1987) 1-8.

5. Hofmeyr, S. A., and Forrest, S.: Arclitecture for an artificial immune system. Evolutionary Computation, $8(4)$ (2000) 443-473.

6. Holland, J. H.: Arlaptation in Natural and Artificial Systcms. Ann Arbor, MI: Lniversity of Michigan Pross (1975).

7. Huang, C.-F.: A Study of Mate Sclection in Genctic Algorithms. Doctoral dissertation. Ann Arbor, MI: Luiversity of Michigan, Electrical Engincering and Computer Scicuce (2002).

8. Miller, R. G.: Beyoud AÑOVA, Basics of Applied Statistics. John Wiiley aud Sons (1986).

9. Witcluell, M.: An Introduction to Genetic Algorithms. Cambridge, MA: MIT Press (1996).

10. Pcrclsou, A. S.: Immunc network theory. Immunol. Rev., 110 (1989) 5-36.

11. Smith, R.. Forrest, S., and Perclson, A. S.: Scarching for Diverse, Coopcrative. Populations with Genctic Algorithms. Evolutionary Computation, 1(2) (1993) 127149.

12. Vlachos, C., Williams, D., aud Gomm, J. B.: Geuctic: Approach to Deccutralized PI Coutroller Tuning for Multivariable Processes. IEE Proc. Control Thcory and Applications, 146 (1999), 58-64. 